\title{
AMORA: EL INICIO DE LA LITERATURA SÁFICA EN MÉXICO
}

\section{AMORA: THE FIRST LESBIAN NOVEL IN MEXICO}

\author{
Jorge Luis Gallegos Vargas \\ Benemérita Universidad Autónoma de Puebla (México)
}

\section{RESUMEN}

A pesar de que los estudios sobre la literatura lésbica ha permanecido al margen del canon, muchos han sido los escritos que han ficcionalizado los acercamientos eróticos de mujeres que aman a otras mujeres.

Amora (1989), de la escritora veracruzana Rosa María Roffiel, está considerada como la primera novela en nuestro país en abordar el amor entre dos Evas de forma explícita. A este título se añaden los de No hay princesa sin dragón (2004) de Ana Klein, Manual de la buena lesbiana (2009) de Ana Francis Mor, Contarte en lésbico (2010) de Elena Madrigal, sólo por nombrar algunos.

En este trabajo, se hace una revisión sobre Amora y cuáles han sido las contribuciones que ha hecho tanto a la literatura mexicana como a las letras sáficas, entresacando de las características eróticas y feministas, desde la teoría queer.

Palabras clave: lesbianismo, literatura, feminismo, continnum lésbico.

\section{ABSTRACT}

Although studies on lesbian literature have remained outside the canon, many have been the writings that have fictionalized the erotic approaches of women who love other women.

Amora (1989), it's a book for Rosamaría Roffiel; it is considerated the first novel in Mexito to talk about for the love between two Evas explicitly. To this title are added those of No hay princesa sin dragón (2004) by Ana Klein, Manual de la buena lesbiana (2009) by Ana Francis Mor, Contarte en lésbico (2010) by Elena Madrigal, just to name a few.

This work, is a review for Amora and what have been the contributions that she has done both to Mexican literature and to the Sapphic letters, separating from erotic and feminist characteristics, from queer theory.

Keywords: lesbianism, literature, feminism, lesbian continnum. 
Que la primera novela mexicana abiertamente lésbica se titule Amora no es fortuito. Desde el inicio se advierte que se hablará del amor en femenino, sáfico; la feminización de éste se llevará a cabo durante el discurrir de la trama, dando una perspectiva en la que existe cabida para el amor lésbico: no sólo se puede hablar de amor sino de amora. Además, la terminación en «a» da la impresión de ser un juego de palabras, una sentencia: se debe tener amor-a la vida, a las mujeres y amor-a las lesbianas, dando como consecuencia una transgresión lingüística.

La historia muestra la perspectiva de Guadalupe, contándonos una historia desde un narrador autodiegético. Amora -personaja- narra desde un discurso confesional, da cuenta de su historia desde un «yo» autobiográfico. El discurso directo se refleja en las constantes notas y aclaraciones dentro de la historia de algunos vocablos propios del argot homosexual'.

La autobiografía es el móvil principal de esta historia; en ella se da cuenta de un fragmento de la vida de Roffiel contada a través de su personaja. A través de la literatura, la autora lleva al ámbito público aquello que la cultura heterocéntrica-patriarcal ha mantenido en silencio; según David Córdoba García «el secreto y el desvelamiento, es de una política de enunciación: quién y en qué situación tiene la legitimidad de tomar la palabra para definir y señalar una realidad (en este caso la homosexualidad» (Córdoba, 2005: 51). Así, la autoficción le sirve para evidenciar desde la intimidad, para contar una historia transgresora que cuestiona el falocentrismo y los heterocentrismos sociales, culturales y literarios.

Amora es autobiográfica; en el paratexto que aparece al inicio del libro la autora revela: «[s]í, en efecto, esta es una novela muy autobiográfica. Casi todas las personajas existen. Casi todos los nombres fueron cambiados. Y casi todo ocurrió realmente» (Roffiel, 2009: 9). Esta primera confesión revela un texto en el que se crea a sí misma; la autointerpretación nos sitúa en una posición en la que no existe posibilidad de distinguir entre ficción y realidad.

Phillippe Lejeune afirma que es «un relato retrospectivo en prosa que una persona real hace de su propia existencia, poniendo énfasis en su vida individual, y, en particular, en la historia de su personalidad» (cit. pos. Sánchez, 2012: 9). Gracias a esta definición, se puede decir que Amora es un viaje en el que existe una triada entre narradora, autora y personaja; estos tres elementos se fraguan uno con otro para dar como resultado una relación identitaria significativa: los tres elementos fungen como uno mismo, asumiendo una postura definida desde un sujeto-histórico o como narrador que cuenta sus propias vivencias.

1 Por ejemplo, se definen la palabras buga: «[m]ujer que, en apariencia, se relaciona sexualmente sólo con hombres》 (17), masoca: «[d]e masoquista, o sea, aquellas y aquellos que gozan el azote y sus derivados» (56), closetera: «[q]uienes -por circunstancias diversas- guardan su homosexualidad en el closet» (65), o bien bicicletear: «[d]e bicicleta, como se conoce a los bisexuales: aquellos seres que no tienen problemas de estacionamiento. La bicicleteada se puede practicar cíclica, alternada o simultáneamente» (65). 
En la autobiografía, el lector asume un contrato definido como pacto autobiográfico:

[p]ara ejecutar el contrato que queda implícitamente firmado entre el autor y el lector en el momento en el que el segundo se acerca a la obra del primero, hay que tener en cuenta que antes ha de haberse cumplimentado un pacto previo, que no es otro que el compromiso del autor consigo mismo respecto a su identidad y a la veracidad de lo narrado. Se ha de garantizar, por tanto, que el narrador que habla de sí mismo y que de lo que sucedió en el pasado se identifica con quien firma el libro -y a quien, en consecuencia, se le adjudica la autoría- y que lo que cuenta en un texto es un expediente de realidad, [...], que espera o exige al máximo de correspondencia entre el texto y la realidad nombrada por éste (Sánchez, 2012: 11-12).

Esto quiere decir que se está frente a un texto en el que, si asumimos el pacto autobiográfico, lo ahí descrito en realidad sucedió, aún y a pesar de que el lector no puede saber si se está relatando un hecho que pasó o bien inexistente; no obstante, este pacto autobiográfico se da desde cómo el lector asume la lectura como verosímil; por tanto, es un artificio de su propia historia de vida, de su propia voz.

Zoé Jiménez Corretjer explica que el discurso testimonial halla «una denuncia a sus circunstancias pasadas, un comentario sobre su realidad y sus sufrimientos así como un documento histórico» (Jiménez, 2001: 105). Roffiel utiliza el testimonio para denunciar no sólo la situación de las mujeres, sino también el de las lesbianas en un México cargado de estigmas lesbofóbicos; evidencia cómo es que éstas son capaces de circunscribir su historia en una Historia que las ha negado.

Así, el acto autobiográfico-confesional radica, para Pozuelo Yvancos en:

...que el autor, narrador y personaje se constituyen en el mismo acto y en simultaneidad [...]: no se puede «poner en cuestión» lo dicho por el narrador en tanto su estatuto es el de personaje, sin poner en cuestión lo dicho por el narrador y personaje se constituyen en el mismo acto y en simultaneidad [...]. Ello explica que el género suscite tantos debates en el estatuto de «sinceridad» [...], [pues] toda autobiografía viene afectada por la pregunta sobre su sinceridad en la medida en que el acto performativo y el cognoscitivo coinciden en uno solo (cit.pos. Sánchez, 2012: 16).

Las fechas que aparecen al finalizar el texto, así como los lugares donde fue escrita la obra, lo dotan de la idea de que se trata de un hecho verosímil ${ }^{2}$. Otro paratexto importante es el epígrafe tomado de la autobiografía de Audre Lorde:

2 Estas fechas son tres: México, D.F. Otoño de 1983; Sherman Oaks, Cal. Primavera de 1989; México, D.F. Verano de 1989. 
Mi padre dejó su huella psíquica en mí, silente, intensa, imperdonable. Pero la suya fue una presencia distante. Son las imágenes de mujeres, flameantes cual antorchas, las que adornan y definen las fronteras de mi jornada, las que se yerguen como diques entre mi ser y el caos. Son las imágenes de mujeres, bondadosas y crueles, las que me conducen al hogar. Audre Lorde Zami, a new spelling of my name (Roffiel, 2009: 11).

El fragmento de la poeta lesbiana, feminista y negra no es gratuito. Ambas escritoras, a pesar de ser de lugares y culturas diferentes, tienen mucho en común: influyeron de manera importante para la literatura sáfica-feminista de sus países, además de usar la autobiografía para autoexplorarse; esta cita expone que se abordará la historia de una mujer y cómo ésta es consecuencia de su relación con otras mujeres.

Iris Kelly explica que la biomitografía, término acuñado por Audre, es una «nueva forma de autobiografía [que] demuestra la necesidad de enseñar nuestras historias a otros y compartir nuestras experiencias, pero a través de un personaje ficticio» (Kelly, 2007:2). En las líneas de Amora, Roffiel se autorrepresenta sin necesidad de especificar que Guadalupe es Rosamaría; la autora cuenta su propia historia desde un personaje ficticio desde el autoconocimiento.

Audre Lorde explica: «lt's a biomythography, wich is really fiction. It has the elements of biography and history of myth. In other words, it's fiction built from many sources. This is one way of expanding our vision» (cit. pos. Sánchez, 2010: 68); es decir, la biomitografía es una autobiografía que se construye a partir de la yuxtaposición de diferentes elementos que conforman el corpus de la historia. En su autobiografía novelada Roffiel recrea una historia fragmentada, una historia de múltiples «yoes» que conviven en la protagonista: el femenino, el lésbico, el activista, el político, el que actúa desde y para la sororidad: un yo polifónico.

La autobiografía supone un proceso de confesión; Judith Butler argumenta:

...tener una confesión que hacer equivale también a poseer palabras que han sido retenidas durante algún tiempo. Tener una confesión que hacer significa que todavía no ha sido hecha, que está ahí, casi formulada en palabras, pero que el que habla está contenida y que el hablante se ha retirado de la relación hasta cierto punto (Butler, 2006: 235).

Gracias a estos elementos, la autobiografía -biomitografía- sirve como móvil para revelar detalles íntimos de la vida de la autora, de decodificar y transgredir las normas impuestas por el régimen machista-patriarcal, de exteriorizar lo oculto, lo prohibido, de socializar una sexualidad reprimida: la lésbica, desarrollando una escritura de resistencia y enfrentando los preceptos hetero-falocéntricos. También, hace un autoexamen, se pone en contacto con 
su yo profundo y asume una postura de reivindicación, pretendiendo concientizar a las y los lectores de la existencia e importancia de las lesbianas en la sociedad, constituyéndolas como un cuerpo político y de participación social ${ }^{3}$.

Adrienne Rich propone la denuncia de la invisibilización de las lesbianas gracias a la heterosexualidad obligatoria; para ello, propone enfocar al lesbianismo desde un continuum lésbico, entendido como la unión de todas las mujeres:

...que de una u otra forma se alejan de la heterosexualidad e intentan crear o reforzar los vínculos entre mujeres que de una $u$ otra forma se alejan de la heterosexualidad e intentan crear o reforzar vínculos entre mujeres, compartiendo sus energías en la perspectiva de la lucha en contra del sistema patriarcal (cit. pos. Falquet, 2010: 25).

El continuum lésbico evidencia un discurso feminista; para Aralia López «es el producto [...] constitutivo de la mujer como sujeto de la Historia y la Filosofía, manifestación de su autoconciencia tanto genérica como individual en el desarrollo de su objetivación para sí» (2000: 5); y es precisamente el discurso feminista, presente en esta obra, la forma en la que se evidencia la carga semántica negativa al que no sólo las mujeres, sino también las lesbianas, han sido objeto; a través de la biomotografía y de Lupe, Roffiel toma conciencia de su homosexulidad y alienta a otras mujeres a vivir fuera del clóset.

La lectura de Norma del periódico Uno más uno sirve para identificar cómo se configura el cuerpo homosexual en la cultura mexicana:

La homosexualidad es una anormalidad. [...]. La ciencia ha descubierto que las personas timocéntricas, es decir, aquellas en quienes la glándula Timo continúa en funciones después de la pubertad, tienen tendencias homosexuales, sean hombres o mujeres. [...] el individuo sigue aniñado $y$, misteriosamente, desarrolla tendencias hacia el mismo sexo. Es débil físicamente y con frecuencia enfermizo, no suele ser longevo. [...] influye también en el sistema nervioso y sus efectos alcanzan psíquicamente al sujeto. Por tanto, el homosexual no es un delincuente; es un deficiente endócrino (Roffiel, 2009: 63).

Esta nota contrapone los conceptos establecidos por la teoría de género, la cual explica que la construcción de la identidad genérica es a partir del desenvolvimiento del individuo en la cultura: el género es cultural y no biológico. A través de lo leído en el periódico se impone un primer estereotipo de género: la homosexualidad como enfermedad neurológica y psíquica y, por ende, puede ser curada; no obstante aclara: el homosexual es un enfermo que quebranta a la sociedad.

3 Un elemento más que habla de la verosimilitud de la historia es la inclusión de casos reales; ejemplo de ello es la violación de Marta, caso registrado por el Centro de Apoyo a Mujeres Violadas en 1983. 
La deslegitimización de los estereotipos es una de las tareas principales de la performatividad. El sujeto queer se construye a partir de la construcción de actos performativos, los cuales van adquiriendo significaciones a través del discurso. En la obra de Roffiel, la primera ruptura con los estereotipos femeninos es el nombre, en el cual la personaja principal lleva una marca indeleble. Guadalupe es el nombre con el que se conoce a la Virgen del Tepeyac; es decir, la personaja carga el estigma de la virgen, mártir y madre, el cual se rompe conforme avanza la historia y se adhiere a un sistema lejos de ideologías patriarcales. Es el nombre de una mujer que, en apariencia, se apega a construcciones culturales masculinas, representa la condición femenina de un México heterocéntrico y, al mismo tiempo, simboliza una contradicción: una virgen sáfica.

Guadalupe se inserta en una familia de cinco hermanos, dos mujeres y tres hombres perteneciente a la clase media, madre divorciada y padre ausente; posee estudios comerciales, periodista autodidacta, trabaja desde los dieciséis años, se autoproclama feminista y dejó de ser virgen a los veinte, además de no creer en el matrimonio. Esta descripción presenta a una mujer cuya condición, a mediados de los ochenta, aún no era bien vista en la sociedad: la que rompe con esquemas clásicos de la cultura patriarcal; la ausencia del padre, manifestada desde el epígrafe, se refuerza con su propia descripción. Al provenir de una familia numerosa, su destino era renunciar a la realización personal para que sus hermanos varones pudiesen tener acceso al ámbito público; no obstante, transforma esos convencionalismos.

El feminismo es parte importante dentro de la conformación del discurso lésbico. El inicio de la historia es contundente: «- ¡Los hombres son una subcategoría!» (Roffiel, 2009: 13). Esta primera frase emitida por Claudia habla de una postura radical, representa una ideología que reproduce los mismos errores que el sistema patriarcal: el rechazo, la no inclusión. Líneas más adelante Claudia define, desde su perspectiva, a los hombres. Esta clasificación otorga una separación sexo-genérica. Por un lado, los estereotipa, pero por el otro, repite paradigmas imperantes en una sociedad machista: los hombres son una subcategoría, pero también son un mal indispensable; para ella los hay de dos tipos: los plásticos -usan marcas reconocidas y cuidan su apariencia- y los pseudointelectuales -usan mezclilla, cabello largo, barba y leen Proceso.

El feminismo radical de Claudia se convierte en un pseudofeminismo. Ocupa el discurso feminista como pantalla pues se asume desde un discurso machista: se define como puta por tener una relación con un casado y el cual le advirtió, desde un inicio, que no se involucraría con ella sentimentalmente. Así, repite roles sexo-genéricos que le competen a la mujer: la amante sólo puede ser vista como objeto erótico carente de sentimientos. 
La novela critica constantemente el discurso machista. Lupe trabaja en un grupo de ayuda médica, psicológica y legal para mujeres violadas; las leyes se encuentran diseñadas para beneficio de los hombres, le da la razón a los que delinquen, a los que atacan sexualmente a las mujeres, considerando como único delito el que sea ella quien tenga que demostrar que es víctima. La novela describe el caso de una mujer que fue víctima de agresiones sexuales en 1983 registrado en el Centro de Apoyo a Mujeres Violadas:

Se llama Marta, tiene veinticuatro años, salió con dos compañeros de su trabajo y otra amiga más. Fueron a una fiesta en un departamento de la colonia Roma [...]. Caminaron por el pasillo hasta la última recámara. Él miró hacia donde estaba su amigo y le hizo una seña que Marta no entendió en ese momento. [...] Comenzaron a forcejear. Él la golpeó [...]. Le desgarró la ropa, le bajó las pantimedias y se las arrancó con todo y zapatos.

La penetró por delante y por atrás, le mordió los senos hasta casi arrancarle los pezones [...]. Cuando al fin él eyaculó, Marta suspiró. [...] - ¿Qué te piensas, hija de la chingada, que ya acabamos? [...] La golpeó más. Le metió su miembro en el ano y después en la boca. [...] Esta vez le eyaculó en la cara. El semen se le metió a Marta por la nariz, por los ojos, por la boca. Le escurrió por el cuello, hasta las orejas. Ella se incorporó bruscamente y comenzó a vomitar [...].

-Pero si sabe el nombre del tipo, el lugar donde trabaja, donde vive, ¿̇por qué no se le puede meter a la cárcel?

-Porque en este país, el delito de violación es el único donde la víctima tiene que demostrar que es víctima (Roffiel, 2009: 36-38).

La violación física enfrenta a la mujer ante su debilidad jurídica. El que una de las víctimas de violación se llame Rosa María, igual que la autora, testifica que todas las mujeres son violables: la violación de una es la de todas. La violencia no sólo es física; el falocentrismo obliga a las mujeres a sentirse ultrajadas con acciones, miradas y agresiones verbales con frases como: «iंTe la meto? $\dot{\imath}$ Te la mamo? Oye, güera, si me muero quién te encuera y te mete la manguera, mamacita mamazota vieja puta» (Roffiel, 2009: 55).

La agresión verbal funciona como sometimiento simbólico. David Córdoba explica que el uso del insulto es un proceso a través del cual «el sujeto homosexual es constituido como excluido, abyecto, como sujeto no legítimo en un orden o régimen (hetero)sexual» (Córdova, 2005: 59). Las personajas se construyen como lo excluido, lo diferente, lo ilegítimo, confrontando los regímenes de la heteronormatividad.

Lupe se deconstruye desde el feminismo, configurándose como una mujer capaz de cuestionar el sistema heteropatriarcal y la división de roles asignados por él: 
Yo, la rara. La desadaptada en silencio. La que nunca entendió por qué no era como las demás. Qué lejos esa mañana de octubre de 1977 en que oí hablar a las feministas por primera vez y me dije [...], «Pero si soy feminista, y no lo sabía!» [...]. Acudí a mi primera reunión en casa de Marta Lamas como quien acude a una ineludible cita con lo desconocido. [...] Comenzamos a hablar de abortos, amantes, virginidades perdidas. [...] ¡Con qué orgullo empecé a portar el estigma del feminismo! Bola de viejas locas, guangas, desocupadas. Bola de lesbianas, antihombres. Bola de feas y amargadas. [...], las mujeres del futuro van a tener que agradecernos muchas cosas a nosotras las pioneras del decir que no, del atrevernos a pensar y a desafiar, a vivir solas, a ser independientes, a correr riesgos, a negarnos a ser objetos sexuales, a enfrentarnos con una nueva mentalidad a una sociedad secular y patriarcal. [...] Para muchos, feminista es sinónimo de lesbiana. Pero ni todas las feministas son lesbianas, ni -desafortunadamente- todas las lesbianas son feministas (Roffiel, 2009: 41-42).

La repetición de las ofensas es el móvil que lleva al sujeto queer a la reivindicación. Mientras Claudia y Guadalupe caminaban abrazadas por la zona Rosa, recibieron palabras peyorativas como tortilleras y manfloras. Amora explica que la palabra manflora le gusta, puesto que suena a yerba olorosa, a ser mitológico o el nombre de un hada; la palabra tortillera se explica porque se cree que cuando dos mujeres frotan su pubis se reproduce el movimiento de las palmas cuando se hacen tortillas, además de ser una actividad que, culturalmente, se le encarga a ellas. La resignificación de ambos términos, vistos desde una explicación lésbico-feminista, contradice los preceptos del discurso falocéntrico, convirtiéndose en un espacio de dignificación: ser manflora acerca a la naturaleza, a lo simbólico, ser tortillera acerca a la feminidad.

Por otra parte, la palabra lesbiana es peyorativa; la carga semántica de la misma ha hecho que parezca fuerte, desagradable, trayendo a cuestas significaciones erróneas:

-A mí la palabra lesbiana [...] [m]e parece fuerte, desagradable.

-[...]. Es por la carga cultural tan negativa que tiene. [...] siento que de tanto usarla diferente, las lesbianas feministas le hemos dado un nuevo valor, la hemos rescatado del fango de la historia.

-[...]. La gente tiene una imagen muy estereotipada de la lesbiana: marimacha, de pantalones, chamarra de cuero, pelo rasurado. Cuando te les presentas, femenina, dulcecita, cariñosa y amable, pues les rompes los esquemas $y$, a veces, hasta llegan a agarrar cierta conciencia (Roffiel, 2009: 98).

Esta cita ejemplifica cómo se da la performatividad de género. De repetir la palabra lesbiana Lupe ha comprendido que las mujeres que aman a otras mujeres la han resemantizado; alejarse del estereotipo de la machorra ha hecho que se comience a ver a las lesbianas como un auténtico y legítimo otro. 
Guadalupe tiene que enfrentar una doble carga ideológica por sus filiaciones políticas: ser lesbiana feminista la hace vulnerable ante la mirada heterocéntrica. El performativo se da cuando Guadalupe esclarece, de forma irónica, qué son las lesbianas:

...algunas feministas somos lesbianas, o sea, somos mujeres que amamos a otras mujeres, o sea que en realidad también somos personas, [...], nacemos, crecemos, nos reproducimos y morimos... igualito que el resto de la raza humana; nos gustan los helados y los tacos; [...] tenemos que trabajar para pagar la renta; nos dan hasta por debajo de la lengua como a Lupita d'Alessio; tomamos camiones, peseros y hasta el Metro; pertenecemos a toda las religiones, ideologías políticas y signos zodiacales y, como dice Rita Mae Brown, venimos en todos los colores y sabores. Sí, como a ustedes, nos tocó nacer y vivir en el planeta Tierra, siglo xx y para colmo en México Distrito Federal, así que algunas estamos un poquito neuróticas, [...] estamos retacadas de clichés, de conductas aprendidas, trampas, autosabotajes, limitaciones, en fin, vaina y media (Roffiel, 2009: 43).

Mediante el símil, Lupe va formando y confrontando la situación de las lesbianas. Las comparaciones sirven para identificarlas como un otro con las mismas características que aquellas que son consideradas normales. Líneas más adelante añade:

...habría que aprender a amar de otra manera. Cambiar las canciones rancheras y los boleros por una música propia [...]. Cómo me gustaría sacar un desplegado [...], algo así como una invitación a las lesbianas que aún repiten los patrones de dominación tan comunes en las relaciones amorosas heterosexuales: amemos diferente, sin cortarnos las venas, sin amenazar con tirarnos desde un puente en el periférico, terminar vomitando en Garibaldi o bajándole la novia a la amiga nada más para que vean qué chingona vengo este año, es decir, no amemos así como dicen que amamos las lesbianas (Roffiel, 2009: 43).

Con la sentencia de amar de distinta manera coloca a lo lésbico en un nivel alejado de los estereotipos. La performatividad de género se da por la necesidad de romper paradigmas sociales, de la mirada histórica, del ojo falocéntrico que opera como aparato represivo del discurso. Lo queer se evidencia por esa necesidad de establecer lo lesbiano como diferente, que convive en lo cotidiano, en la cultura popular; a través de la palabra ejerce una severa crítica a aquellas que, siendo lesbianas, repiten estereotipos de género.

Para Judith Butler, el término lesbiana ha sido omitido del lenguaje, sirviendo como estrategia para ser incluido dentro del concepto género, puesto que:

...la introducción de las lesbianas equivale a la introducción de un nuevo género, un género no natural que conducirá a la destrucción de la maternidad y que está ligado a las luchas feministas por los derechos reproductivos, es una presuposición irremediablemente homofóbica y misógina a la vez (Butler, 2006: 267). 
Gracias a la plática que sostienen Guadalupe, su sobrina Mercedes y Verónica, amiga de la segunda, plantea la necesidad de introyectar desde la infancia significados opuestos a los implantados. Mercedes, sin saber la preferencia sexual de su tía, la cuestiona sobre las lesbianas; Verónica cree que son degeneradas y violadoras, Amora argumenta: «son mujeres comunes y silvestres, de todos los colores, edades, nacionalidades, y profesiones que simplemente aman a otras mujeres en lugar de amar a los hombres» (Roffiel, 2009:120). Así, ser lesbiana es, simplemente, un acto performativo que irrumpe en el plano de lo heteronormativo y quien asume su disidencia sexual se evidencia desde un yo queer.

El discurso feminista sirve a la novela para cuestionar el discurso heteropatriarcal; por ejemplo, se cree que la penetración es la única forma del goce sexual, así como la virginidad una virtud femenina. Mercedes pregunta a su tía cómo es que se lleva a cabo la penetración en el acto sexual lésbico; Guadalupe explica: «[u]stedes creen que el amor sexual se reduce a que te metan un pene y ya. Se olvidan de los besos, las caricias, las palabras, los roces...» (Roffiel, 2009: 121); la ausencia de penetración y la presencia del juego erótico son la forma por la que se lleva a cabo una relación sexual lésbica, reforzando la idea de que la mujer es más sensitiva que el hombre.

Otra crítica al sistema patriarcal se evidencia cuando se referencia a las leyes, tachando al país como un lugar en el que protegen únicamente a los varones y diciendo también que «[c]ada caminata por el DF me confirma mi teoría de que la Tierra es un planeta de castigo, y que nacer mujer y vivir en esta ciudad es una de las últimas pruebas que debe pasar el ser humano para llegar a elevadísimos planos del espíritu» (Roffiel, 2009: 96). Además, a través de los chistes de Pepito y los corridos se muestra el discurso machista: la cultura de masas repite y forja idearios equívocos de la cultura heteropatriacal.

El mito de Penélope se reinventa y deja al descubierto que las historias de las mujeres están encerradas bajo el paradigma de los hilos, figura a través de la cual se habla de que la existencia de ellas ha sido a cortada:

Se me ocurre que nuestras abuelas y nuestras madres dejaron buena parte de su vida colgando de hilachos: los del trapo de sacudir que les sacudió las ilusiones, los de la jerga que les restregó sus sueños, los de las sábanas de un sexo sinónimo de sacrificio y, sobre todo, de los dolorosos hilos de una existencia a medias. Mujeres cuya vida ha transcurrido y transcurre envuelta entre madejas de estambre, unidas a lienzos de tela por un cordón umbilical hecho de hebras, prendido al cuerpo por agujas o ganchos de tejer. Y otras, que lejos de permitir que la costura, el bordado y el tejido las sometieran como esclavas, lograron convertirlos en un arte cotidiano (Roffiel, 2009: 103-104). 
Este mito reinterpretado ejemplifica la utopía feminista en la que a pesar del sometimiento de la vida privada, lo han convertido en transgresión de las normas, resignificando espacios y actividades, considerados propias de la mujer, un espacio en el que se rompen los artificios, resemantizando la costura como un arte cotidiano, apropiándose del mito y del espacio, por tanto, se resignifica desde una perspectiva; la literatura es un lugar para una Penélope subvertida:

\begin{abstract}
Hay textos cuidadosamente bordados como los de Roa Bustos y Guimaraes Rosa; otros llenos de colores, como los de García Márquez y Vargas Llosa. Los hay confeccionados a mano, como los de Elena Garro, o cosidos aceleradamente en una máquina Singer, como los de la China Mendoza. Los hay escritos con hilos y suspiros, como los de Benedetti y Galeano, o bien con metálicas madejas de angustias, como los de Sábato y Cortázar. Son muy pocos los cosidos a ovarios como los de Rosario Castellanos y Elena Poniatowska. Y está la maravillosa filigrana de la poesía que requiere de hilos de puntadas especiales capaces de crear instantes, de rimar encuentros, de inventar momentos (Roffiel, 2009: 104-105).
\end{abstract}

Es así como tilda dos figuras literarias importantes -Castellanos y Poniatowska- como creadoras fuertes, audaces, transgresoras, escritoras con ovarios; feminiza a Márquez y Vargas Llosa: en la literatura la mujer reformula normas, es un lugar de subversión; la misma Guadalupe -Roffiel- se equipara con las escritoras al contar su historia con ovarios.

Los hilos en la literatura se equiparan al arquetipo de la araña. Zoé Jiménez revela que es una figura dual:

[l]a araña, por tejer y destejer, se asocia con los principios activos de construcción y destrucción. La araña crea y recrea como la mujer. Y es importante también si observamos su significado destructivo. La araña construye y al mismo tiempo puede obrar y decidir sobre sus víctimas. Destruir en ella es otra forma de construir (2001: 85).

Es decir, Rosario, Elena y Rosamaría son arañas literarias capaces de tejer historias fuera de los cánones patriarcales, de destruir significados impuestos por la cultura machista y crea un nuevo paradigma literario: historias feministas que retratan de manera verosímil a la mujer, apropiándose de los mitos a través de éstas historias y resignificar.

Estas historias contadas con ovarios son también las que llevan a Roffiel a ironizar a figuras femeninas que transgredieron el falogocentrismo de la época en la que vivieron. Así, encontramos la beatificación de personajes importantes como Franca Basaglia, Josefa Ortiz de Domínguez y la Malinche; canoniza a Juana de Arco y Marilyn Monroe, la última considerada como estereotipo de la belleza femenina occidental. Además, resemantiza a 
la Virgen de Guadalupe, quien desde un punto de vista ideológico no podría ayudar a una lesbiana. También, crea a la Virgen del Orgasmo Perpetuo, a quien se encomienda para poder entablar una relación con Claudia, a la Virgen de las Mil Especies, a quien le encarga la comida, y, finalmente a la Patroncita de los Milagros Urbanos. Aralia López explica que a través de la presencia de:

...un novedoso panteón profano de mártires y santas, conscientes 0 inconscientemente feministas, son [...] ángeles tutelares en sus momentos de apuros [...] el yo autobiográfico de la narradora se diluye en un «nosotras» testimonial. Y no se trata de mujeres extraordinarias, sino comunes y corrientes. Lo extraordinario, quizás, es el compromiso solidario y feminista, así como la ruptura con los modelos masculinos de socialización del poder (López, 2000: 7).

A través de la parodia, las advocaciones generan nuevos significados de mujeres subversivas que han cuestionado las estructuras falocéntricas. La ficcionalización de mujeres transgresoras sirve para cuestionar el sistema patriarcal mexicano, todas ellas mujeres rebeldes que vivieron pasiones sáficas -Tina Modotti, Frida Khalo y Nancy Cárdenas.

Al mismo tiempo, se plantea que el discurso machista es reproducido por la madre. Las diferencias entre hombres y mujeres de la familia de Lupe se dan cuando la madre de ésta decidió inscribirla en una escuela comercial para que le ayudara a pagar los estudios de sus hermanos varones. Las hermanas reprodujeron lo esperado para una mujer: una cultora de belleza, la otra vendedora de perfumes en Palacio de Hierro, ambas esperando el momento idóneo para casarse y dedicarse a sus hijos y maridos. A pesar de que los sueños de ser psicóloga o pediatra de Lupe se truncaron, eso hizo que se convirtiera en una mujer transgresora: la ruptura con la imagen materna se dio a pesar de los reproches y estigmas que suponen vivir sola; esta última acción representa un peligro de violación, así como independencia económica, moral y psicológica; nuevamente se apropia de un símbolo para resignificarlo; se desvincula a la mujer de la maternidad: mujer y madre no son sinónimos.

Además, Roffiel traslada a su protagonista al DF, ciudad que en apariencia es peligrosa para ellas, en la que convergerán, desde un punto de vista feminista casi radical, hombres insensibles y mujeres promotoras del machismo. A pesar de ello, la sororidad es determinante para la novela; ejemplo de ello es la relación amistosa que tiene con Vica, con quien comparte trabajo y participan del Movimiento de Liberación de la Mujer.

Conjuntamente, la performatividad de género se establece desde una crítica a la heterosexualidad ortodoxa. En principio, Claudia se niega la posibilidad de entregarse a las pasiones sáficas; ella declara, en distintas ocasiones, no ser lesbiana, quiere casarse, tener hijos y necesita de los hombres, posee «exceso de núcleos heterosexuales» (Roffiel, 2009: 
130). Mariana, amiga de Guadalupe, critica las actitudes de Claudia: «- ¡Es increíble! Cogen con los tipos, no tienen orgasmos, les molesta la penetración y se sienten vacías, pero eso sí, les conflictúa andar con una porque, aunque les supermovemos el tapete, resulta que ellas sí están muy definidas, [...]» (Roffiel, 2009: 130).

Para Claudia, Guadalupe funciona como un espejo; por un lado, cuestiona constantemente la homosexualidad y los paradigmas sociales que giran en torno a ella, calificándola como antinatural, como una actitud que provocará una confrontación al «qué dirán», un conflicto interno: no se asume lesbiana a pesar de sentir atracción física y emocional por Lupe, representando la heterosexualidad ortodoxa; por el otro, Guadalupe representa la homosexualidad asumida: se enorgullece de ser mujer y lesbiana, de amar y ser amada por otra mujer, funciona como espejo en el que se centra el amor que Claudia se tiene a sí misma: ama lo que es, lo que se niega a sí misma que es.

Más adelante, Claudia se da cuenta del amor hacia Guadalupe, asume su disidencia sexual y se reconoce como otro no heterosexual, indaga en su «yo» lésbico. Así, el constante rechazo al lesbianismo, genera que Claudia se desconstruya y reconstruya desde lo marginal, desde lo abyecto, desestabilizando la categoría heterosexual y haciendo inteligible los significados y significantes negativos que la sociedad heteropatriarcal ha impuesto:

Pues sí, volví con Claudia. [...]. Terminó ya con sus dos galanes. [...]. Dice que cuando estaba con ellos pensaba en mí. Que nuestro amor se le convirtió en una urgente necesidad. [...] Abrí las piernas. Ella se dejó caer de espaldas a mí y se acomodó en el nido que formaba mi cuerpo. La rodeé con mis brazos. Mi mejilla rozaba su pelo. Nos tomamos de las dos manos y, al compás de la música, hicimos el amor con la yema de nuestros pulgares. [...]. Y el resto de la noche nos amamos, así como seguramente aman las diosas (Roffiel, 2009: 184).

El «final feliz», muy al estilo del melodrama, ejemplifica cómo a través de un discurso feminista y trasgresor va reconstruyéndose a partir de la norma heterosexual, pauta que cuestiona y subvierte mediante la sumisión de un «yo» lésbico, dotando de significaciones lo lesboerótico, configurando conductas, actos y comportamientos impuestos por la cultura patriarcal. Claudia, a través del reforzamiento discursivo, acepta su homosexualidad y se enfrenta a una relación lesboerótica con Claudia, entregándose al goce de los idilos sáficos.

La reivindicación femenina y el uso del continnum lésbico, pintan en la novela la urgencia de contar desde un discurso culturalmente silenciado, el planteamiento de los idilios sáficos y la apropiación de las historias para resignificarlas.

La escritura autobiográfica exhibe a una autora con la necesidad de mostrar un yo lésbico, de deconstruirse a través de Guadalupe; expone a su personaja en un México 